09,05

\title{
Излучающие гетероструктуры с двухслойной квантовой ямой InGaAs/GaAsSb/GaAs и ферромагнитным слоем GaMnAs
}

\author{
() О.В. Вихрова, Ю.А. Данилов, Б.Н. Звонков, П.Б. Демина, \\ М.В. Дорохин, И.Л. Калентьева, А.В. Кудрин
}

Научно-исследовательский фризико-технический институт

Нижегородского государственного университета им. Н.И. Лобачевского,

Нижний Новгород, Россия

E-mail: vikhrova@nifti.unn.ru

Исследованы излучательные и магнитные свойства гетероструктур нового типа с двухслойной квантовой ямой $\mathrm{InGaAs} / \mathrm{GaAsSb} / \mathrm{GaAs}$ и ферромагнитным слоем GaMnAs. Установлено наличие циркулярной поляризации электролюминесцентного излучения в диапазоне температур от 10 до $160 \mathrm{~K}$. Магнитополевые зависимости степени циркулярной поляризации являются нелинейными с петлей гистерезиса при температурах от 10 до $50 \mathrm{~K}$, при более высоких температурах они становятся линейными. Величина поляризации при насыщении намагниченности GaMnAs в поле 2000 Ое сохраняется на уровне $\sim 0.2 \%$.

Работа выполнена в рамках реализации государственного задания (проект № 8.1751.2017/ПЧ Минобрнауки России) при финансовой поддержке РФФИ (гранты № 15-02-07824_a, 16-07-01102_a, 17-37-80008_мол_эв_а), стипендии (конкурс СП-2015) и гранта Президента Российской Федерации (№ МК-8221.2016.2).

DOI: $10.21883 /$ FTT.2017.11.45060.09k

\section{1. Введение}

Арсенид-галлиевые структуры с активной областью, представляющей собой двухслойную квантовую яму $\mathrm{In}_{x} \mathrm{Ga}_{1-x} \mathrm{As} / \mathrm{GaAs}_{1-y} \mathrm{Sb}_{y} / \mathrm{GaAs}$, активно исследуются для разработки светодиодов с длиной волны излучения вблизи $1.3 \mu \mathrm{m}$ (высокоскоростного канала волоконнооптической связи) [1,2]. При определенных толщинах соответствующих напряженных слоев и содержании индия и сурьмы в них можно достичь высокой интенсивности фотолюминесцентного излучения на непрямых переходах между зоной проводимости слоя $\mathrm{In}_{x} \mathrm{Ga}_{1-x} \mathrm{As}$ и валентной зоной слоя $\mathrm{GaAs}_{1-y} \mathrm{Sb}_{y}$ [1]. Кроме того, излучательные характеристики значительным образом зависят от совершенства гетерограницы $\mathrm{In}_{x} \mathrm{Ga}_{1-x} \mathrm{As} / \mathrm{GaAs}_{1-y} \mathrm{Sb}_{y}$ и порядка выращивания слоев. Ранее было исследовано влияние технологических параметров получения GaAs-гетероструктур с двухслойной квантовой ямой $\operatorname{In}_{x} \mathrm{Ga}_{1-x} \mathrm{As} / \mathrm{GaAs}_{1-y} \mathrm{Sb}_{y}$ методом МОС-гидридной эпитаксии на их излучательные характеристики. С учетом анализа представленных в литературе данных по получению напряженных слоев $\mathrm{GaAs}_{1-y} \mathrm{Sb}_{y}$ и двухслойных квантовых ям $\mathrm{In}_{x} \mathrm{Ga}_{1-x} \mathrm{As} / \mathrm{GaAs}_{1-y} \mathrm{Sb}_{y} / \mathrm{GaAs}$ [1-4] экспериментально были определены температурный диапазон $\left(560-580^{\circ} \mathrm{C}\right)$ и соотношение потоков элементов V и III групп $(\lesssim 1)$ для процесса выращивания методом МОС-гидридной эпитаксии слоя $\mathrm{GaAs}_{1-y} \mathrm{Sb}_{y}(0.1 \leq y \leq 0.25)$ хорошего качества с целью создания двухслойной квантовой ямы $[5,6]$. Подтверждено, что, как и в случае молекулярно-лучевой эпитаксии (МЛЭ) [7,8], первоначальное выращивание слоя твердого раствора $\mathrm{GaAs}_{1-y} \mathrm{Sb}_{y}$ способствует значительному возрастанию интенсивности и увеличению длины волны фотолюминесцентного излучения гетеронаноструктур с двухслойной квантовой ямой $\mathrm{In}_{x} \mathrm{Ga}_{1-x} \mathrm{As} / \mathrm{GaAs}_{1-y} \mathrm{Sb}_{y}$ [5].

В настоящей работе показано, что введение в структуру светодиодов с двухслойной ямой слоя ферромагнитного полупроводника GaMnAs в качестве инжектора спин-поляризованных носителей (формирование спинового светоизлучающего диода) может расширить область их применения за счет появления циркулярной поляризации излучения. Спиновые светоизлучающие диоды - диоды с циркулярно-поляризованным излучением - используются как источники циркулярнополяризованного оптического излучения в оптоэлектронных схемах. Работа спинового светоизлучающего диода основана на одновременном и независимом варьировании как интенсивности электролюминесценции, так и степени циркулярной поляризации электролюминесцентного излучения. Это значит, что информация может передаваться одновременно и независимо как посредством интенсивности излучения, так и посредством степени его поляризации. Поэтому использование спиновых светоизлучающих диодов значительным образом может повысить плотность данных, передаваемых по оптическим каналам связи. Отличительной особенностью спинового светоизлучающего диода является наличие в нем ферромагнитного слоя (полупроводника или металла), который функционирует как инжектор спин-поляризованных носителей. Именно инжекция спин-поляризованных носителей обеспечивает циркулярно-поляризованную электролюминесценцию, а управление магнитными параметрами ферромагнитного слоя позволяет управлять степенью циркулярной поляризации. 


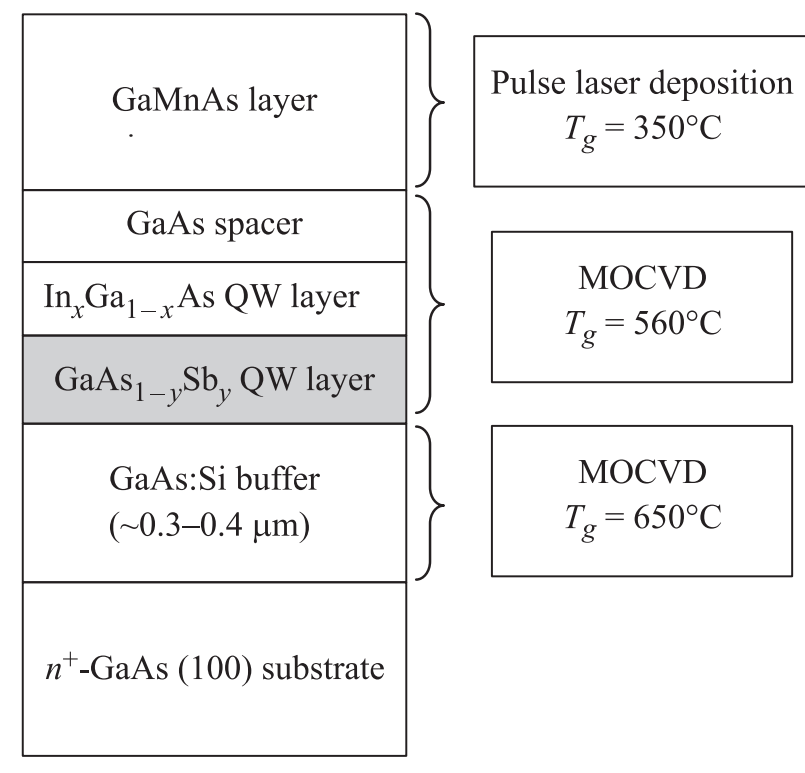

Рис. 1. Схематическое изображение гетеронаноструктуры $\mathrm{GaAs} / \mathrm{In}_{x} \mathrm{Ga}_{1-x} \mathrm{As} / \mathrm{GaAs}_{1-y} \mathrm{Sb}_{y} / \mathrm{GaAs}$ с инжектирующим слоем ферромагнитного полупроводника GaMnAs.

\section{2. Методика эксперимента}

В данной работе исследовались диодные $(p-i-n)$ гетероструктуры, содержащие двухслойную квантовую яму $n$-GaAs/GaAsSb/InGaAs и слой полупроводника GaMnAs p-типа проводимости. Образцы были получены сочетанием методов МОС-гидридной эпитаксии (МОСГЭ) и импульсного лазерного нанесения (ИЛН) в едином ростовом цикле [9]. На подложках $n^{+}$-GaAs методом МОСГЭ выращивали: буферный слой $n$-GaAs, слои квантовой ямы $\mathrm{GaAs}_{1-x} \mathrm{Sb}_{x}(x=0.2), \mathrm{In}_{y} \mathrm{Ga}_{1-y} \mathrm{As}$ $(y=0.2)$ и спейсер $\mathrm{GaAs}$ толщиной $d_{s}=9-18 \mathrm{~nm}$. Затем при $350^{\circ} \mathrm{C}$ методом импульсного лазерного нанесения формировали слой GaMnAs толщиной $\sim 100 \mathrm{~nm}$ (отношение времен распыления мишеней $\mathrm{Mn}$ и GaAs составляло 0.15) и покровный слой GaAs толщиной $\sim 14 \mathrm{~nm}$. Схематическое изображение структур представлено на рис. 1, параметры структур показаны в таблице. Структура № 7975 является контрольной. Она изготовлена на подложке полуизолирующего $\mathrm{GaAs}$, содержит буферный слой нелегированного GaAs (МОСГЭ) и слой GaMnAs, изготовленный в тех же технологических условиях, что и в случае диодных структур.

Исследовались спектры фото- (ФЛ) и электролюминесценции (ЭЛ) изготовленных структур в зависимости от температуры измерений (от 10 до $300 \mathrm{~K}$ ) и мощности оптической или электрической накачки. Для возбуждения фотолюминесценции использовали лазеры с длиной волны $\lambda=632.5 \mathrm{~nm}$ (мощность $30 \mathrm{~mW}$ ) или $\lambda=532 \mathrm{~nm}$ (с варьированием мощности от 0.1 до $114 \mathrm{~mW}$ ). Электролюминесценцию исследовали на изготовленных с применением фотолитографии и химического травления меза-диодах (диаметр $500 \mu \mathrm{m})$ с металлическим (Au) омическим контактом к слою GaMnAs. Магнитополевые зависимости степени циркулярной поляризации электролюминесценции $\left(P_{\mathrm{EL}}\right)$ исследовали в геометрии Фарадея по стандартной схеме с использованием четвертьволновой пластины [10]. Измерение намагниченности производили при $300 \mathrm{~K}$ с использованием магнитометра с переменным градиентом магнитного поля.

\section{3. Экспериментальные результаты и их обсуждение}

Из представленных в таблице данных видно, что содержание марганца (определяемое соотношением времен распыления лазерным излучением соответствующих мишеней) в инжекторном слое GaAs достаточно высокое и может составлять $\sim 10$ at.\%. Ранее было показано, что указанный полупроводник является ферромагнитным и обладает температурой Кюри $\sim 50-70 \mathrm{~K}$ по исследованиям магнитополевых зависимостей сопротивления Холла [11]. Наблюдался аномальный эффект Холла и отрицательное магнетосопротивление. Гальваномагнитные исследования тестового образца № 7975 в температурном диапазоне $10-300 \mathrm{~K}$ подтвердили этот факт. Слой $\mathrm{GaMnAs}$ также имеет включения второй фазы, сохраняющей ферромагнитные свойства вплоть до комнатной температуры. На это указывают измеренные нами магнитополевые зависимости намагниченности (рис. 2) и наличие петли гистерезиса на зависимости угла поворота плоскости поляризации от магнитного поля, полученной в процессе исследования магнитооптического эффекта Керра [11]. Включения второй фазы могут представлять собой полуметаллические кластеры MnAs и/или $\mathrm{MnGa}$ с температурой Кюри вблизи $315 \mathrm{~K}$ и свыше $600 \mathrm{~K}$ соответственно [12].

Изготовленные структуры имеют достаточно высокое структурное и оптическое качество, на что указывает сохранение излучательных свойств при температурах $160-220 \mathrm{~K}$. Полученные спектры фотолюминесценции образцов содержат пики, соответствующие переходам в

Технологические параметры серии гетеронаноструктур $\mathrm{GaAs} / \mathrm{In}_{x} \mathrm{Ga}_{1-x} \mathrm{As} / \mathrm{GaAs}_{1-y} \mathrm{Sb}_{y} / \mathrm{GaAs} \quad(x \approx 0.2, \quad y \approx 0.2) \quad \mathrm{c}$ инжектирующим слоем GaMnAs, изготовленных на пластинах $n^{+}$-GaAs $(100)$

\begin{tabular}{c|c|c|c|c|c|c}
\hline $\begin{array}{c}\text { № } \\
\text { структуры }\end{array}$ & $\begin{array}{c}h_{\mathrm{GaAsSb}}, \\
\mathrm{nm}\end{array}$ & $\begin{array}{c}h_{\mathrm{InGaAs}}, \\
\mathrm{nm}\end{array}$ & $Y_{\mathrm{Mn}}$ & $\begin{array}{c}d_{s}, \\
\mathrm{~nm}\end{array}$ & $\begin{array}{c}T_{g}(\mathrm{QW}), \\
{ }^{\circ} \mathrm{C}\end{array}$ & $\begin{array}{c}h_{\text {cap }}, \\
\mathrm{nm}\end{array}$ \\
\hline 7969 & 8 & 6 & 0.13 & 18 & 560 & $10-12$ \\
7971 & 8 & 6 & 0.13 & 9 & 560 & $10-12$ \\
7975 & - & - & 0.13 & - & - & $10-12$
\end{tabular}

Примечание. $Y_{\mathrm{Mn}}=t_{\mathrm{Mn}} /\left(t_{\mathrm{Mn}}+t_{\mathrm{GaAs}}\right)$, где $t_{\mathrm{Mn}}$ и $t_{\mathrm{GaAs}}-$ времена распыления мишеней марганца и арсенида галлия. Структура № 7975 изготовлена на подложке полуизолирующего GaAs и содержит буферный слой нелегированного GaAs и слой GaMnAs толщиной $~ 100 \mathrm{~nm}$. 


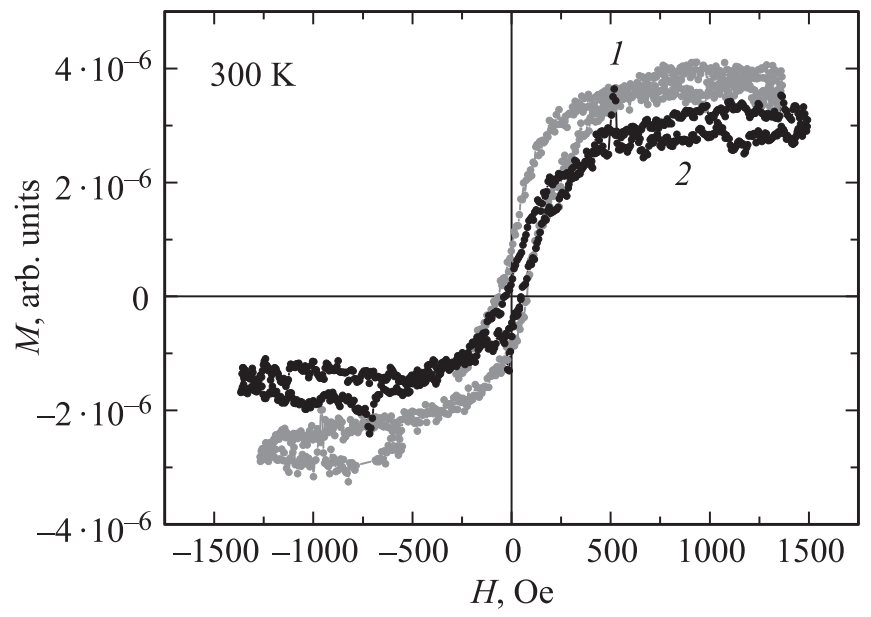

Рис. 2. Магнитополевая зависимость намагниченности структур при $300 \mathrm{~K}$. Толщина спейсерного слоя $d_{s}=9$ (1), $18 \mathrm{~nm}(2)$.

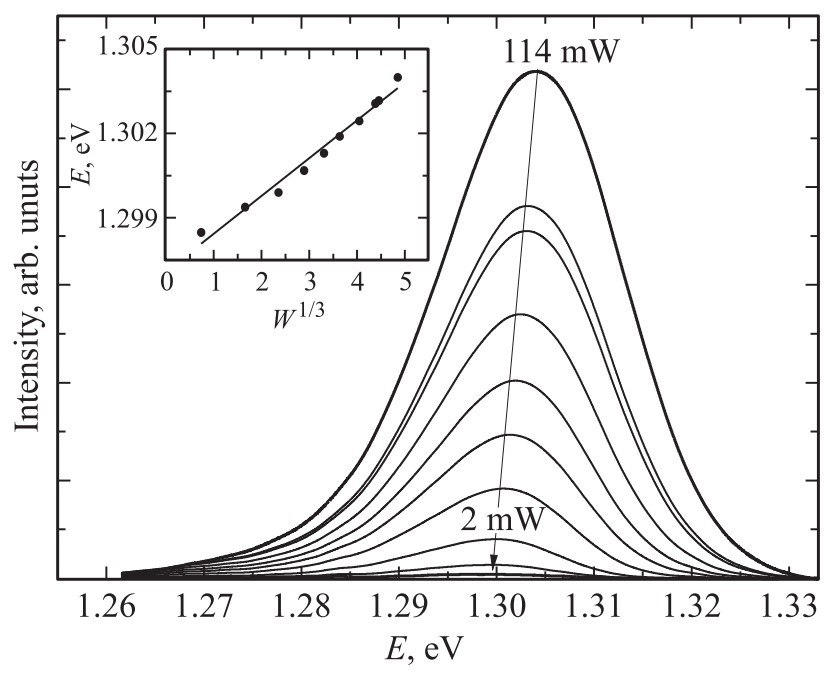

Pис. 3. Зависимость интенсивности фотолюминесценции при $10 \mathrm{~K}$ от мощности накачки лазерным излучением для структуры № 7969 с GaAs спейсером толщиной $18 \mathrm{~nm}$ между двухслойной квантовой ямой и слоем GaMnAs (см. таблицу).

двухслойной квантовой яме вблизи энергии $1.29-1.3 \mathrm{eV}$ при температуре $10 \mathrm{~K}$. Зависимость энергии пика фотолюминесценции от мощности накачки $E\left(W^{1 / 3}\right)$ имеет линейный вид (рис. 3), что отвечает непрямому в координатном пространстве переходу между зоной проводимости слоя $\operatorname{In}_{y} \mathrm{Ga}_{1-y}$ As и валентной зоной слоя $\mathrm{GaAs}_{1-x} \mathrm{Sb}_{x}$ и может указывать на формирование гетероперехода второго рода [13].

Уменьшение толщины спейсера GaAs между слоем GaMnAs и квантовой ямой с 18 до $9 \mathrm{~nm}$ приводит к значительному (на порядок) снижению интенсивности фотолюминесцентного излучения квантовой ямы. Данный эффект может быть обусловлен усилением вклада безызлучательной рекомбинации при приближении к активной области структуры низкотемпературного слоя GaMnAs, который содержит такие дефекты, как атомы Mn в междоузлии и антиструктурные дефекты $\left(\mathrm{As}_{\mathrm{Ga}}\right)$ [14]. Кроме того, атомы Mn могут образовывать комплексы с указанными точечными дефектами [15]. Bсе вышеперечисленные дефекты могут оказывать влияние на процесс рекомбинации.

Исследование температурных зависимостей электролюминесценции образцов светодиодов, изготовленных на основе структур с двухслойными квантовыми ямами $\mathrm{InGaAs} / \mathrm{GaAsSb} / \mathrm{GaAs}$ и ферромагнитным инжектирующим слоем GaMnAs, выявило наличие излучения квантовой ямы в диапазоне температур $10-220 \mathrm{~K}$ (рис. 4). Зависимости интегральной интенсивности электролюминесценции для обоих образцов носят активационный характер. Энергия активации $\left(E_{a}\right)$ составляет $\sim 90 \mathrm{meV}$ в случае образца со спейсерным слоем GaAs толщиной $18 \mathrm{~nm}$ и уменьшается до $35 \mathrm{meV}$ для структуры с $d_{s}=9 \mathrm{~nm}$. Объяснение понижения $E_{a}$ логично связать с „приближением““ к активной области светодиода каналов безызлучательной рекомбинации, связанных с точечными дефектами и их комплексами, возникающими в слое GaMnAs вследствие низкой температуры выращивания и легирования марганцем значительно выше предела его растворимости $\sim 10^{19} \mathrm{~cm}^{-3}[16]$.

Исследования магнитополевых зависимостей циркулярной поляризации электролюминесценции показали, что при температуре измерений $10 \mathrm{~K}$ величина $P_{\mathrm{EL}}$ выходит на насыщение в поле $\sim 2000$ Ое, где достигает $0.2 \%$. Такой вид зависимости $P_{\mathrm{EL}}$ с петлей гистерезиса и насыщением указывает на преимущественную спиновую поляризацию носителей в активной области, связанную с наличием ферромагнитных свойств у исследуемых структур. Нелинейная зависимость $P_{\mathrm{EL}}$ наблюдается вплоть до температуры $50 \mathrm{~K}$, интерпретируемой как температура Кюри инжектора GaMnAs (вставка на

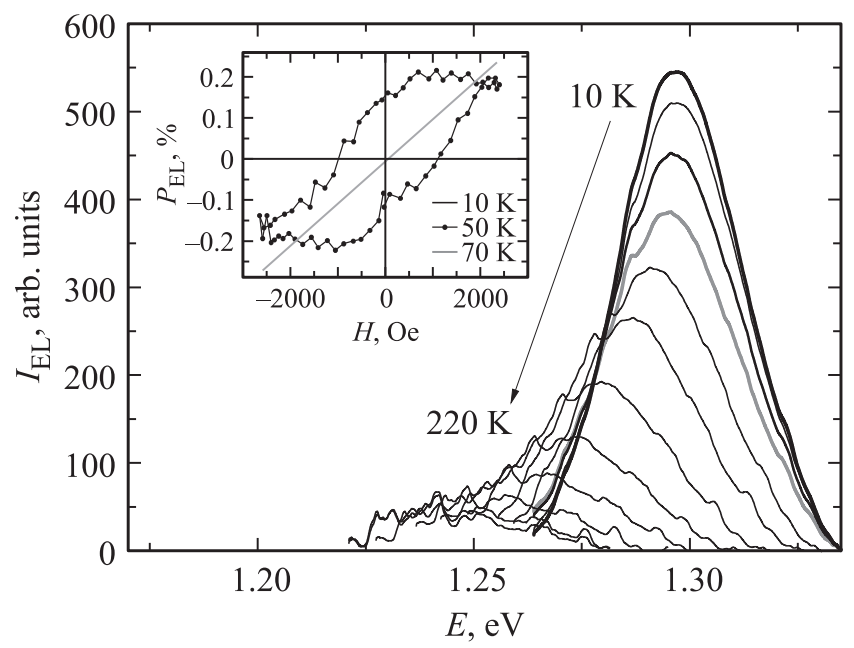

Рис. 4. Влияние температуры измерения на спектры ЭЛ диода на основе структуры с $d_{s}=9 \mathrm{~nm}$ при токе $I=30 \mathrm{~mA}$. На вставке приведены магнитополевые зависимости $P_{\mathrm{EL}}$. 
рис. 4). Далее вплоть до $\sim 160 \mathrm{~K}$ зависимость $P_{\mathrm{EL}}(H)$ является линейной, а величина $P_{\mathrm{EL}}$ в поле 2000 Ое сохраняется на уровне $\sim 0.2 \%$. Выше $160 \mathrm{~K}$ вследствие низкой интенсивности электролюминесценции погрешность измерений становится сопоставимой с величиной степени циркулярной поляризации.

\section{4. Заключение}

Таким образом, впервые экспериментально исследованы светоизлучающие гетероструктуры нового типа с двухслойными квантовыми ямами InGaAs/GaAsSb/GaAs и ферромагнитным слоем GaMnAs, сформированным методом низкотемпературного импульсного лазерного нанесения. Структуры имеют достаточно высокое оптическое и кристаллическое качество и демонстрируют циркулярно-поляризованное электролюминесцентное излучение с сохранением степени циркулярной поляризации $0.2 \%$ в диапазоне температур $10-160 \mathrm{~K}$.

\section{Список литературы}

[1] M. Peter, K. Winkler, M. Maier, N. Herres, J. Wagner, D. Fekete, K.H. Bachem, D. Richards. Appl. Phys. Lett. 67, 2639 (1995).

[2] M. Pristovsek, M. Zorn, U. Zeimer, M. Weyers. J. Cryst. Growth 276, 347 (2005).

[3] C.T. Wan, Y.K. Su, R.W. Chuang, C.Y. Huang, Y.S. Wang, W.C. Chen, H.C. Yu. J. Cryst. Growth 310, 4854 (2008).

[4] Y.K. Su, C.T. Wan, R.W. Chuang, C.Y. Huang, W.C. Chen, Y.S. Wang, H.C. Yu. J. Cryst. Growth 310, 4850 (2008).

[5] Б.Н. Звонков, С.М. Некоркин, О.В. Вихрова, Н.В. Дикарева. ФТП 47, 1231 (2013).

[6] Н.В. Дикарева, О.В. Вихрова, Б.Н. Звонков, Н.В. Малехонова, С.М. Некоркин, А.В. Пирогов, Д.А. Павлов. ФТП 49, $11(2015)$.

[7] Z.C. Niu, X.H. Xu, H.Q. Ni, Y.Q. Xu, Z.H. He, Q. Han, R.H. Wu. J. Cryst. Growth 278, 558 (2005).

[8] J.F. Klem, O. Blum, S.R. Kurtz, I.J. Fritz, K.D. Choquette. J. Vac. Sci. Technol. B 18, 1605 (2000).

[9] B.N. Zvonkov, O.V. Vikhrova, Yu.A. Danilov, P.B. Demina, M.V. Dorokhin, V.V. Podol'skiı̌, E.S. Demidov, Yu.N. Drozdov, M.V. Sapozhnikov. J. Opt. Technol. 75, 389 (2008).

[10] M. Holub, P. Bhattacharya. J. Phys. D: Appl. Phys. 40, R179 (2007).

[11] Б.Н. Звонков, О.В. Вихрова, Ю.А. Данилов, Ю.Н. Дроздов, А.В. Кудрин, М.В. Сапожников. ФТТ 52, 2124 (2010).

[12] M. Tanaka. Mat. Sci. Eng. B 31, 117 (1995).

[13] О.В. Вихрова, М.В. Дорохин, П.Б. Дёмина, Б.Н. Звонков, А.В. Здоровейщев, Ю.А. Данилов, И.Л. Калентьева. Письма в ЖТФ 40, 20, 96 (2014).

[14] М.Д. Вилисова, А.Е. Куницын, Л.Г. Лаврентьева, В.В. Преображенский, М.А. Путято, Б.Р. Семягин, С.Е. Торопов, В.В. Чалдышев. ФТП 36, 1025 (2002).

[15] А.П. Горшков, И.А. Карпович, Е.Д. Павлова, И.Л. Калентьева. ФТП 46, 194 (2012).

[16] J.F. Xu, P.M. Thibado, C. Awo-Affouda, F. Ramos, V.P. LaBella. J. Vac. Sci. Technol. B 25, 1476 (2007). 